\title{
EL DERECHO PENAL EN LA ENCRUCIJADA DEL AÑO 2000
}

Enrique Ruiz Vadillo

Presidente de la Sala de lo Penal del Tribunal Supremo.

Vocal Permaneste de la Comisión General de Codificación y Profesor de Universidad.

\section{SUMARIO}

Introducción.

Crisis de valores.

La persona humana y la convivencia.

La Constitución Española.

Europa y el Derecho Penal.

La sociedad y el Derecho Penal.

La culpabilidad.

Indispensabilidad del Derecho Penal.

La imparcelabilidad del Derecho Penal.

La paradoja del Derecho Penal.

La duda, signo primario de este derecho.

La imaginación en el Derecho punitivo.

Criminalización-Descriminalización.

El mundo penitenciario.

Las penas privativas de libertad.

La reinserción del delicuente.

El proceso penal.

La misión del juez penal.

El Jurado.

Consideraciones finales.

\section{Introducción}

Desde esta Melilla que para los españoles peninsulares e isleños 
ofrece tan especiales connotaciones de consideración, admiración y afecto quiero enviaros un saludo lleno de respeto, de cariño y de estímulo si uds. me lo aceptan para mantener vivos vuestros ideales y propósitos.

Como el cabo Tres Forcas defiende Melilla de los vientos del Oeste y la laguna litoral de bu-Areg, (o Mar Chica) actua de estabilizadora del clima de esta bellísima Ciudad, la recia personalidad de sus ciudadanos y al mismo tiempo su espíritu generoso y cosmopolita sirvan para configurar unas señas muy precisas de identidad, compatibles con el respeto y la comprensión hacia distintas formas de entender la vida y hacia diversas culturas. Acaso sea esta uno de los mejores caminos para ejemplarizarnos en la tolerancia y en la consideración a los demás, esencia misma de la democracia. No es imprescindible que coincidamos en todo, probablemente ni siquiera es bueno, basta la identidad de ilusiones para construir un mundo mejor, más libre, más auténtico, más humano y, en definitiva, más justo.

La confluencia de poblaciones de muy distinto origen y características en esta encantadora Melilla es un dato aleccionador -Hebreos, mahometanos, (con un fondo bereber e importante incidencia árabe) y europeos- porque, ha sido tradicionalmente ejemplar. La proyección de la Comunidad Europea y del Consejo de Europa en este crisol de culturas, de ideales y de bellezas, en esta preciosa Ciudad, tan española y universal, fortalecer, sin duda, las magníficas perspectivas que su historia y su presente hacen legítimamente esperar.

Melilla, ha dicho nuestro alcalde D. Gonzalo Hernández Martínez forma parte de la Comunidad Económica Europea y por ello el ciudadano melillense y sus instituciones son conscientes del papel que puede jugar entre los europeos y los africanos. Ese es uno de los retos más auténticamente atractivos de esta Ciudad.

\section{Crisis de valores}

El mundo al que pertenecemos está pasando, no sufriendo, una profunda evolución. Aquellos bienes que hace cincuenta o sesenta años parecian relativamente asentados, no tienen hoy el alcance y la significación primitivos. Poco esfuerzo hay que hacer para demostrarlo: las relaciones de la pareja, de los miembros de la familia nuclear, de los 
educadores y educados, la idea misma de instrucción y formación, la llamada honestidad, el escándalo público tradicional, las ideas religiosas, el derecho a castigar por parte del Estado, no han podido ser insensibles a estos cambios sociales en cuanto a su respectiva incidencia jurídica porque el Derecho o es precisamente una Ciencia social, dinámica y cambiante, o no es nada.

Por supuesto, no voy a entrar en el examen de la positividad o negatividad de esta trasformación. Me limito a constatarla y con enorme respeto para quienes no piensen así, a decir que en mi modesta opinión, toda ella es, en general, favorable a las ideas sustentadoras del Derecho, como son la justicia y el bien común.

Frente a la cifra mágica del año 2000, como ocurrió con otras de análoga significación (1), el mundo se presta a buscar en el horizonte de los días, la clave de la nueva frontera de los tiempos, política, social, económica y jurídicamente, como si se tratara de descubrir lo que hay detrás de ese muro gigantesco enigmático e incierto, sin darse cuenta que sólo un segundo separará, sin solución de continuidad, al siglo que muere y al que nace. No habrá revolución, sino evolución y esta tiene ya signos de identidad inequívocas.

El título de esta charla es una simple concesión a expresiones estereotipadas, pero su contenido quiere ser una reflexión común con este grupo muy cualificado de personas por su preparación y sensibilidad, sobre el futuro inmediato del Derecho Penal.

Por encima de todo hay que conseguir el mayor equilibrio posible entre el desarrollo tecnológico y el progreso humano. Dice Caro Baroja (2) que en todo caso hay datos para suponer que lo que domina es cierto amorfismo moral y que los métodos que se han de aplicar para remediar los excesos a los que conduce la técnica han de ser métodos

(1) Por ejemplo, en la Edad Media que tuvo su origen en el Renacimiento y expresa el tiempo transcurrido desde el siglo V hasta la mitad del siglo XV o sea hasta el año 1453 en que desapareció el Imperio de Oriente con la toma de Constantinopla por los turcos.

(2) Caro Bajoja: "Factores negativos en el desenvolvimiento de Vizcaya en el futuro próximo" (1984-2000). Ponencia General de las Jornadas.

Ruiz Vadillo, Enrique: "Vizcaya y su evolución hacia el futuro". Contribución del Derecho al desarrollo social; pág. 269. En "Factores negativos en la evolución de la sociedad vizcaina". I. Jomadas sobre Vizcaya ante el siglo XXI. Vol. II. 
no basados en la fe religiosa ni en la conciencia moral general o individual, sino en nociones de tipo legal, ante todo. Lo que sucede, en mi opinión, es que la legalidad, sin más, es también un dato insuficiente para sostener válidamente, con legitimidad trascendente o metajurídicapositiva, una estructura y un entramado social consistente, si no hay detrás una conciencia colectiva que asuma, o al menos acepte y respete, el sistema jurídico imperante.

Ahí está la crisis, crisis de crecimiento, al alcanzar las personas colectivamente su mayoría de edad que muchas veces ha sido negada o aminorada con la censura política, jurídica, social o moral. De sujetos pasivos de una relación, han pasado a ser actores, de súbditos a ciudadanos. Esta es la grande y auténtica revolución.

Sólo falta que un consenso real y efectivo permita construír un sistema basado en la libertad y en la igualdad en el que todos respetemos a todos, en función de unas coordenadas de justicia. Este es el papel trascendente del Derecho y de quienes ejercen los poderes del Estado que es la sociedad organizada: de quienes legislan, de quienes gobiernan y de quienes juzgan.

\section{La persona humana y convivencia}

Nuestra Constitución que ofrece una clara naturaleza jusnaturalista y que situa en su primer plano de inquietudes a la persona humana y así lo ha destacado de manera insistente el Profesor Hernández Gil fortalece los principios más esenciales del Derecho Penal, entendido como una unidad estructural (sustantivo, procesal, penitenciario y orgánico); así el principio de legalidad, de culpabilidad (el principio de presunción de inocencia es una clara manifestación de ello, si se presume provisoriamente la inocencia es porque en el polo opuesto hay culpabilidad y correspondiente responsabilidad), de protección de la dignidad humana y de proporcionalidad.

Ahí reside el fortalecimiento del Derecho Penal en centrar los problemas en la persona humana en cuanto a quien delinque y a la víctima. No se habla ya de la honestidad sino de la libertad sexual y manifestaciones de aquella como el adulterio, y el amancebamiento consencuencia de un desamor, han dejado de ser delitos, como acaso suceda pronto con el abandono de familia $y$, dentro de ciertos temperamentos con el escándalo público. 


\section{Constitución Española}

Hacer efectivos los principios constitucionales es tarea fundamental de los Tribunales, en todos los sectores y en cuanto afecta a esta charla, en el campo penal y con ello enlazamos con ideas ya expuestas o que habrán de ser desarrolladas en esta conversación, y en este sentido hay que citar con los profesores Cobo del Rosal y Vives Antón(3) el principio de legalidad del que Beling trazó una distinción entre "tenor literal" y el "significado esencial del referido principio y dentro de él las exigencias de claridad y taxatividad en la determinación de las conductas prohibidas y de las sancionadas aplicables".

En mi modesta opinión y como filosofía del principio creo que todavía hay que añadir otra consecuencia: no sólo que los delitos únicamente existen cuando la Ley los ha configurado como iguales (destinatario el juez ), sino que todas las conductas o hechos con idéntico o análogo relieve jurídico-penal (por ejemplo la delicuencia de los negocios) deben también tipificarse como infracciones penales (destinatario el legislador).

También el principio "non bis in idem", en toda su extensión, en su vertiente material y procesal y con referencia al Derecho Penal y al Administrativo, es básico y se contiene implícitamente en el articulo 25 de la Constitución Española.

Como lo es de igualdad que tiene una doble proyección a juicio de los autores citados (4): hacia el legislador representa una prohibición de las diferencias de trato injustificadas o discriminatorias, frente al juez no representa la exigencia de que supuestos indénticos sean tratados siempre del mismo modo, sino sólo la de que las diferencias se justifiquen argumentalmente. Sin sacarlo de quicio: Que no se puedan asegurar los menores, en cuanto a la vida o que las mujeres con hijos pequeños tengan un horario "ad hoc" no atenta a este principio constitucional. El que desiguala lo desigual, iguala, menos por menos, más.

La presunción de inocencia, consagrada constitucionalmente en el artículo 24.2 de la Constitución representa uno de los pilares del

(3) Cobo del Rosal y Vives Antón: "Derecho Penal. Parte general 2" Ed. Tirant lo Blanch. Derecho, pág. 48 y ss. Valencia 1987.

(4) Idem, pág. 59. 
ordenamiento jurídico, no sólo del Derecho Penal, sino del Derecho todo También tiene una doble proyección frente al legislador imposibilidad de establecer presunciones de culpabilidad o hechos presuntos y en el Derecho Procesal Penal, la prohibición de condenar mientras no se pruebe el hecho determinante del delito (5).

La presunción de inocencia supone que sólo una actividad probatoria de cargo de signo acusatorio, advenida regularmente al proceso y razonablemente suficiente, puede servir para condenar y hacer entrar en juego el artículo 741 de la Ley de Enjuiciamiento Criminal (6).

Finalmente tenemos el principio de proporcionalidad que rige, como dicen Cobos y Vives (7), el establecimiento y aplicación de toda especies de medidas restrictivas de libertad.

\section{Europa y Derecho Penal}

Existe una tendencia inequívoca a la uniformidad europea en la configuración del' Derecho Penal. Si las respuestas al crimen, como dice Mireille Delmas-Marty, están condicionadas por el tiempo y el espacio porque el mismo crimen se configura en cada sociedad según criterios múltiples y a veces contradictorios, en la medida en que el espacio también se configure bajo unos criterios de armonización; en líneas generales, sólo nos quedará como condicionante particularizable de las estructuras jurídicas, al menos las más comunes, el Derecho Mercantil, parte del Civil, grandes sectores del Penal, menos del Administrativo y Político, mucho también en el procesal en cuanto instrumento de garantía de los derechos fundamentales, las notas específicas de cada Pueblo en la medida en que sean determinantes de aspectos

(5) Lo cual no quiere decir que determinadas situaciones de hecho no conduzcan a la agravación de la pena. Por ejemplo, el art. 546 bis b) del Código Penal. No es correcto constitucionalmente ( $y$ así lo ha declarado la Sala $2^{\mathbf{a}}$ del Tribunal Supremo) afirmar que quien posee un establecimiento abierto al público, si recepta es habitual, si lo es, en cambio afirmar que si el receptador es un comerciante la pena puede sufrir una agravación. Lo inaceptable es presumir, sin más, en contra del inculpado. Aunque parezca un juego de palabras, no lo es.

(6) Vázquez Sotelo, José Luis: "Presunción de inocencia del imputado e intima convicción del Tribunal". Gosch Casa Ed. S.A. Barcelona 1984.

(7) Cobo y Vives, Obra citada, pág. 63. 
diferenciadores importantes.

En este sentido, es obligado citar la labor extraordinariamente fecunda que está llevando a cabo el Consejo de Europa, a través de sus distintas organizaciones, últimamente bajo la muy acertada dirección del actual Secretario General, nuestro compatriota D. Marcelino Oreja que ha publicado recientemente un libro sobre Europa ("Europa ¿Para que? Respuestas europeas a problemas actuales") (8). En los muchos años que he tenido la inmensa satisfacción de colaborar en su tarea a través de mi participación en Comités de Expertos, en representación de España (9), puedo decir que los efectos alcanzados me parecen excepcionalmente valiosos precisamente porque surgen de una política serena, equilibrada, técnica también, de los Grupos de Trabajo que sólo persiguen una política de armonización, hasta donde en cada momento es posible, alcanzándose así metas, sin disfunciones ni sobresaltos en el vacío, que irán también dando poco a poco - ya han producido muchos- sus correspondientes frutos.

\section{La Sociedad y el Derecho Penal}

Estos planteamientos exigen una colaboración estrecha de muchos colectivos. La tarea de configurar un nuevo Código Penal, en mi modesta opinión, exige, primero un descubrimiento real y efectivo, en función de unas coordenadas sociales muy precisas descubiertas con seriedad, de los valores que la Comunidad estima básicos y después un pronunciamiento, sobre los mismos principios acabados de exponer, en relación con el sistema punitivo y la dosimetría de las sanciones.

No vamos a hacer un catálogo de problemas pero con la finalidad de reflejar más expresivamente lo que pretendo decir, podamos recordar el

(8) Oreja Elosegui, Marcelino: "Europa ¿Para qué? Respuestas europeas a problemas actuales". Prólogo de Raimond barre 1987.

(9) Ruiz Vadillo, Enrique: “Algunas consideraciones sobre la contribución del Consejo de Europa al desarrollo y perfeccionamiento del Derecho Penal”. Rev. General de Derecho. Valencia, abril-mayo y junio 1985.

Disparidades en el pronunciamiento de las penas $\left(8^{\circ}\right.$ Coloquio Criminológico del Consejo de Europa). Recomendación $n^{\mathbf{2}} \mathrm{R}(87)$ concemiente a la cooperación interestatal europea en materia penal. 
tema de la violación - de mujer, de hombre-, y sus distintas manifestaciones en orden a su punición, de especial gravedad por atentar al valor esencial de la libertad en una de sus principales manifestaciones, la libertad sexual, sobre el que la Sala $2^{\mathrm{a}}$ del Tribunal Supremo dirigió una Exposición al Gobierno, el delito de desórdenes públicos en que acaso conviniera precisar más para evitar qué expresiones de desacuerdo político o laboral puedan generar una infracción penal, el delito de escándalo público que acaso, dados los términos legales del Código Penal, pueden generar situaciones no queridas por el propio legislador, algunas de las modalidades de los delitos mal llamados contra la honestidad, que en definitiva sólo deben defender la libertad sexual, el tema de determinadas imprudencias que no debieran tener cobijo en el texto penal, por ejemplo aquellas que sólo producen daños materiales y así un largo etcétera. Otro tanto podemos decir de los delitos que han sido calificados de opinión, como las injurias a las más altas Magistraturas de la Nación. Pero hay que advertir algo importante no es el juez quien inventó el delito ni quien asoció la pena correspondiente, sino que fue el legislador, tanto el que creó la figura como el que la mantiene. La contribución a que la vida de las personas en sus relaciones con las demás y con el Estado y demás Entes Públicos y privados sea correcta ha de ser finalidad básica del Derecho. Como ha dicho Jescheck la misión del Derecho Penal es proteger la convivencia humana en la Comunidad. Todo lo que nos desvie de este esencial propósito será, en mi opinión, alejarnos de la esencia misma de esta importante área del Ordenamiento Jurídico.

La propia inseguridad ciudadana debe resolverse sobre un contexto de cooperación eficaz de las gentes, de los ciudadanos con las autoridades. Pensar que el Estado y la Administración lo pueden todo y todas las responsabilidades han de recaer sobre ellos es un error. Si algo debe caracterizar a la auténtica democracia frente a las dictaduras es la presencia activa del pueblo, la realidad de un régimen participativo. Otro tanto debemos decir del fenómeno social, gravemente patólogico, de las drogas (10).

(10) Conferencia sobre la prevención de la inseguridad urbana. Barcelona 17-20 noviembre de 1987. La droga y la inseguridad. Consejo de Europa (15.004/09.21). 


\section{La culpabilidad}

La reforma penal de 25 de junio de 1983 , y esperamos que todavía lo será mucho más el próximo Código Penal, ha constituído un evidente mejoramiento del sistema, poniendo el acento, como tiene que ser, en el principio culpabilista a través del párrafo 2 del nuevo artículo 1 que insiste en la exigencia de dolo o culpa que la acción pueda ser penada. Esta declaración, dice Manzanares (11), además de no ser superflua en su alcance general, puede servir para corregir la tradicional exégesis, puramente causal y objetiva, de aquellos delitos cualificados por el resultado que aún subsisten en el Código, como es el caso de los abortos del último párrafo del artículo 411 y del delito contra la salud pública del artículo 348. También a mi juicio en los delitos de lesiones inmodificados tiene proyección el nuevo principio culpabilístico.

\section{Indispensabilidad del Derecho Penal}

El Derecho Penal es, desde luego, un instrumento indispensable para la convivencia y todavía es desgraciadamente impensable una sociedad sin penas privativas de libertad, menos aún sin Derecho Penal, pero puesto que esto es así resulta fundamental reducir sus contornos (descriminalizar) y hacer perder protagonismo a las penas privativas de libertad (despenalizar) acudiendo con prioridad al Derecho Privado (Civil y Comercial o Mercantil y Laboral) y al Administrativo, antes que al Penal para resolver los conflictos sociales. De ahí la trasferencia que de ciertos comportamientos se postula desde el Derecho Penal al Administrativo, aunque haya de advertir el exquisito cuidado que hay que poner en el traslado para que el cambio de naturaleza de la infracción no suponga jamás reducción de garantías ni gravación de la responsabilidad. El ejemplo alemán en este sentido, a través de la ordnungswdrigkeiten, es especialmente ilustrativo. También el ordenamiento italiano (12) se conduce por análogos derroteros y en

\footnotetext{
(11) Manzanares Samaniego, José Luis en "Comentarios al Código Penal". Comares 1987.

(12) V. Ley italian a de 24 de noviembre de 1981 sobre modificación del sistema penal. Boletín de información del Ministerio de Justicia de España, núm. 1.477 de 25 de diciembre de 1987.
} 
parecido sentido el portugués. El proyecto español de 1980 y la PANCP de 1983 parece que aceptan también esta idea, aunque todavía tímidamente.

\section{La imparcelabilidad del Derecho Penal}

Hace un momento hemos expresado la línea de que el Derecho Penal ha de concebirse como una perfecta y sincrónica unidad porque si en algunas de sus proyecciones falta la vigencia de los principios esenciales, la construcción penal en sentido amplio se habrá venido abajo (13).

De ahí que el proceso penal haya de construirse como instrumento de defensa paralelamente de la sociedad y del justiciable y de que en él haya de imperar la idea de la proscripción de toda indefensión, del derecho a no declararse culpable, a utilizar todos los medios necesarios para la defensa del inculpado, el derecho a un proceso sin dilaciones indebidas, el derecho a la impugnación, conforme a las Declaraciones Internacionales y finalmente la necesidad de un proceso inspirado en el principio acusatorio porque se entiende que es el que mejor satisface las exigencias de justicia de nuestra sociedad en el que el juez debe ante todo y sobre todo ser juzgador y sólo juzgador, encomendándose al Ministerio Fiscal la tarea de investigar y, en su caso, de acusar, reservándose al juez la misión de resolver y eventualmente de tomar en el curso del procedimiento determinadas medidas de control jurisdiccional: prisión, entrada y registro en un domicilio, control de correspondencia postal, telegráfica y telefónica, etc.

El juez, en cuanto tal, no puede acusar y, por consiguiente, ni siquiera el actual artículo 733 de la Ley de Enjuiciamiento Criminal le habilita a sustituir al fiscal o eventualmente a otra acusación particular, conforme a la doctrina del Tribunal Constitucional y del Tribunal Supremo, en la tarea acusadora que jamás puede asumir un juez sin quiebra del principio acusatorio.

(13) Ruíz Vadillo, Enrique: "Realidades y perspectivas jurídico-penales en la España de 1986". En Libro-Homenaje al profesor Eduardo Correia. Universidad de Coimbra. 


\section{La paradoja del Derecho Penal}

Cuando el Tribunal Constitucional, a través de una doctrina realmente muy valiosa, ha configurado los perfiles esenciales del Derecho Penal ha diseñado un sistema perfectamente equilibrado en el que se conjugan la necesidad de imponer determinadas sanciones a los infractores de las normas penales con la exigencia de garantizar todos los derechos del justiciable que es propio de un Estado de derecho, democrático y social. Sólo así puede resolverse la gran paradoja del Derecho Penal, que por una parte ofrece la cara agria y hosca de tipos penales y penas y consecuentemente por otro se esfuerza hasta los límites más insospechados en defender al inculpado, en reforzar las garantías y en imponer restricciones extraordinariamente gravosas a la culminación de una sentencia condenatoria. Estableciendo así un sistema que defiende de verdad al ciudadano y a la sociedadd aunque a veces, desde una perspectiva aparencial dé la impresión de que fomenta de alguna manera la seguridad ciudadana y la tranquilidad de las buenas gentes. Esta es la grandeza del Derecho Penal que sólo se percibe bien cuando alguien cerca de nosotros sufre la incidencia de una investigación criminal y después, si da lugar a ello, un proceso penal como acusado.

Todo cuanto sea alejar la visión kafkiana del proceso es bueno. El gran escritor checo que prestó servicios en la carrera judicial supo como pocos expresar la tragedia del sistema penal si entre todos no lo cargamos de sensatez y de humanidad, por encima de las leyes a las que el hombre puede y debe vivificar. Sus obras descubren el perfecto conocimiento de esa realidad, que él supo elevar a la categoria de esperpento y de caricatura

\section{La duda signo primario del Derecho Penal}

Como dice Quintero Olivares (14), la duda hace también constante aparición en el Derecho Penal: sobre qué comportamientos deben recibir graves castigos, sobre dónde reside la legitimidad para decidir lo

(14) Quintero Olivares, Gonzalo: "Derecho Penal. Parte general". Barcelona 1986 Ed. Gráficas Signo pág. 27. 
bueno y lo malo, pues al fin la descripción de esos comportamientos encierra el deseo de sentar qué es precisamente lo bueno y qué es lo malo, sobre cómo y cuánto han de castigarse esas conductas, sobre qué beneficio obtiene la sociedad haciéndolo y así podríamos, dice, alargar casi indefinidamente la relación de dudas que se abre.

Efectivamente, por ello creo que es imprescindible una tarea interdisciplinar en busca de un consenso sobre el que los legisladores puedan después reflexionar y decidir. Principalmente sobre el catálogo de delitos y sobre las penas que a cada uno hayan de asociarse, para ello creo que resulta enormemente significativa coleccionar las penas horizontales en función de su naturaleza y extensión comprobando si los ilícitos que las sirven de base tienen análoga significación y entidad. El ejercicio de este trabajo que he realizado en varias ocasiones, me parece, repito, especialmente interesante (15).

Comprendo la dificultad que comporta conseguir un recto equilibrio punitivo, pero creo que debiera hacerse un mayor esfuerzo en este sentido. Se comparaban hace días las penas de un homicidio, a juicio de la acusación, asesinato; con las injurias al Jefe del Estado o la violación con el homicidio o la detención ilegal con la toma de rehenes, y aunque casi todo es relativo, no cabe duda de que pueden y deben obtenerse unos ciertos diseños rectilíneos de configuración punitiva.

\section{La imaginación en el Derecho punitivo}

Casi todo está inventado en el campo del Derecho, pero la creación dada no implica caer en el estado carencial del silencio y de la inactividad. Antes al contrario, el dinamismo social propio de todo ente vivo, exige la constante búsqueda de nuevas perspectivas y horizontes. Cargar la imaginación, como tuve oportunidad de recordar en las III Jornadas de Derecho Penal celebradas en Aix-En-Provence en 1982

(15) Ruíz Vadillo, Enrique: "La dosimetría penal en el Código español". Anuario de Derecho Penal y Ciencias penales. Madrid 1977. Ruíz Vadillo, Enrique: "Algunas observaciones al proyecto de reforma parcial del Código Penal". Ministerio de Justicia. Centro de publicaciones 1982. 
(16): para dar satisfacción a las necesidades actuales, tema al que se refirió, con la inteligencia que le caracteriza, el profesor Lavasseur, en el Rapport de Síntesis.

Como dice el profesor Muñoz Conde (17), para regular la convivencia entre las personas, se establecen normas vinculantes que deben ser respetados por esas personas, en tanto son miembros de la comunidad. El sistema elegido para solucionar las frustraciones al sistema de expectativas derivado de una norma o conjunto de normas, es la sanción es decir la declaración de que se ha frustrado una expectativa y la consiguiente reacción frente a esa frustración.

Ahora bien, el tema radica en buscar una solución eficiente y equilibrada a la naturaleza de las sanciones. Son muchos los tipos de sanciones y también a este tema hace referencia el citado profesor. La imposición de una sanción se lleva a cabo primariamente a nivel social. Hay pues una escala de correctivos, desde la infracción a comportamientos sociales no obligatorios jurídicamente (los llamados usos sociales, por ejemplo) que se sancionan socialmente: pérdida del saludo, del prestigio, de la consideración el rechazo, etc. hasta la sanción penal pasando por otras también jurídicas, pero de naturaleza civil, mercantil, laboral o administrativa.

A este tema hace referencia una sentencia de la Sala $2^{\mathrm{a}}$ del TS (18) en relación con el delito de desacato, refiriéndolo al derecho-deber de los políticos en el ejercicio de su actividad política de dar cuenta a los ciudadanos de la gestión y administración y dirección de la cosa pública que tienen encomendada por tener a su cargo el cuidado de una parte de la Comunidad en un determinado sector. Han de proceder de

(16) Un resumen de mi Ponencia se publicó en la Revista del Poder Judicial, $1^{\bullet}$ Epoca, número 5 diciembre de 1982 con el título "Descriminación y Derecho Penal". También se publicó en el Boletín Oficial del Ministerio de Justicia, de Portugal.

Posteriormente he tratado nuevamente del tema de la descriminalización en la misma Revista, 2" Epoca número 7 bajo el título: "El futuro inmediato del Derecho Penal, las tendencias descrminalizaciones y las fórmulas de sustitución de las penas privativas de libertad de corta duración". Septiembre 1987.

(17) Mufioz Conde, Francisco: "Introducción al Derecho Penal" Bosch Casa Editorial S.A. 1975, pág. 12. Este esquema, dice, coincide con el planteamiento funcionalista de Talcott Persons: "El sistema actual".

(18) Sentencia del Tribunal Supremo, Sala $2^{\mathrm{a}}$ de 18 de enero de 1988. 
forma correcta, con el respeto debido a quienes critican y a sus propios destinatarios, pero los excesos verbales o escritos, los radicalismos, las descalificaciones, los malos modos, si existen, si la conducta no es tipificable en el Código Penal (pensamos en el artículo 8.1) y en el elemento subjetivo o culpabilístico de las injurias y desacatos (figuras delictivas emparentadas entre sí) han de tener sanción en el ámbito social y político, no en el jurídico-penal.

Otro tanto hay que decir de la lucha política constitutiva, en principio de infracciones sociales que si existen han de tener correcciones sociales. La libertad de expresión representa uno de los pilares más esenciales de una sociedad libre y democrática. El periodismo ha de tener unos cauces muy amplios para desarrollar su importante actividad, indispensable para que un Pueblo pueda vivir informado, plataforma básica también para su actuación como ciudadano.

\section{Criminalización-descriminalización}

Un replanteamiento general de los catálogos delictivos es urgente. Descubrir el movimiento criminalización-descriminalización, dice la Profesora Delmas-Marty (19), es admitir inmediatamente la paradoja de una política criminal que define su propio objeto, que lo delimita entre todos los comportamientos de rechazo de las normas, existiendo unos que aceptan con su silencio y otros que designa con la etiqueta de infracción, desviación o infracción-desviación frente a los que ha de responder. Criminalización y descriminalización son, a la vez, objeto y sujeto, movimientos de política criminal y definición de la política criminal: las consecuencias son también las causas. Pero este movimiento tiene que ser dirigido a la obtención de un perfecto equilibrio en las tipologías y las sanciones que hoy falta.

En este sentido, como contrapunto y como objeto de meditación, bueno para estudiar aquellas posturas, como las de Hulsman, que rechazo porque me parecen ahora utópicas, pero que pueden ofrecer campos de visualización del problema, especialmente interesantes, acaso perspectivas de futuro nada desdeñables.

(19) Delmas-Marty, Mireille: "Modelos actuales de Política criminal". Presentación: Marino Barbero Santos. Ministerio de Justicia. Colección "Temas penales" Serie A. $n^{2} 4$ Madrid 1986. 


\section{EI mundo penitenciario}

El mundo penitenciario es especialmente significativo. Solo una buena organización en este sentido puede alentar la esperanza de la resocialización. Nuestra Ley Orgánica General Penitenciaria creemos que es absolutamente ejemplar y ajustada a las más estrictas exigencias del Consejo de Europa. Basta para comprobarlo con la lectura imparcial y desapasionada de la misma en relación con las Reglas Penitenciarias Europeas adoptadas por el Comité de Ministros el 12 de febrero de 1987 con ocasión de la 404 reunión de Delegados de Ministros.

$\mathrm{Ni}$ la venganza, ni el odio ni el rechazo incondicionado conducen a ninguna parte. El profesor Neuman (20), el profesor García Valdés (21) y otros varios penalistas y penitenciarios lo han puesto de relieve muy significativamente.

Lo que no supone, antes del contrario, abandonar a la víctima a la que por exigencia de justicia elemental y por un principio básico de justicia hay que prestar toda la asistencia posible. De ahí la preocupación ejemplar del profesor Beristain (22).

La cárcel no puede ser un hotel de lujo pero tampoco hemos de buscar de ello un lugar en el que la infrahumanidad tenga su asiento (23).

\section{Las penas privativas de libertad}

A ello ha de unirse la nueva consideración de la pena privativa de libertad. Mi larga experiencia judicial y penitenciaria conducen a una afirmación que con las excepciones oportunas, ofrece un panorama desolador: la pena de cárcel es contraproducente y es difícil o imposi-

(20) Neuman, Elías: "Crónica de muertes silenciadas". Villa Beroto, 14 marzo 1978. Idem: "Enigma para jueces". 1977.

(21) García Valdes, Carlos: "Comentarios a la legislación peninteciaria". Ed. Civitas S.A. 1982.

(22) Beristain Ipiña, Antonio: "Crisis del Derecho represivo". Cuadernos para el Diálogo.

(23) Consejo de Europa: "Les droits de l'homme dans les prison". Estrasburgo 1986. Se examina el tema a nivel nacional e internacional. 
ble imaginar, pese al esfuerzo de tantas personas, una regeneración a su través. Por consiguiente hay que pensar que en este momento la prisión debe reservarse sólo para aquellos delitos que inciden gravemente en la convivencia social, por el tiempo indispensable y para los demás casos en los que se crea indispensable la intervención del Derecho Penal, buscar fórmulas alternativas de sanción: interdicciones, suspensión, privación de derechos, trabajo social o comunitario y la multa o pena pecuniaria, en su modalidad de día-multa.

Con una salvedad: que la jerarquía de gravedades ha de medirse en función de unos nuevos parámetros de conformidad con las actuales exigencias sociales, en el sentido por ejemplo de que el delito fiscal o, en general, gran parte de la llamada delicuencia económica o criminalidad de los negocios que aparentemente podría hacer pensar no necesita de la prisión, ofrece en cambio, desde todos los puntos de vista, una extraordinaria gravedad, como han puesto de relieve insistentemente los profesores Barbero, Bajo, Beristain Fernández Albor y otros muchos en España y Delmas-Marty, Pedrazzi,Triedeman etc. en el extranjero.

Por ello, es decir, porque se teme más que nunca a la cárcel, se discute hoy la constitucionalidad del artículo 91 del Código Penal que permite la sustitución de la pena de multa por el arresto sustitutorio, tema zanjado por el Tribunal Constitucional hace muy pocos días, pero que deja vivo, desde el punto de vista social un problema cuyas deficultades y complejidades a nadie pueden pasar desapercibidas.

\section{Reinserción de delincuente}

Hemos de procurar una nueva configuración del Derecho Penal orientado fundamentalmente a la reinserción del delincuente, haciendo compatible esta búsqueda de la resocialización con la indispensable defensa social a partir de sus nuevos y alentadores planteamientos. En este sentido son muchas las ideas que pugnan por alcanzar protagonismo en cuanto significan hitos en esta importante conquista social; las conocidas quiebras a la libertad de determinación de la persona humana: la herencia, el medio ambiente, las estructuras sociales, tantas veces de signo criminógeno; la inutilidad tantas veces de tantas penas que se pierden en el vacio del sufrimiento, del coste social y de la imposible 
reparación a la víctima; las responsabilidades de otros muchos factores en el delito que no se exteriorizan pero que todos sabemos han incidido en la infracción penal y que no soportan proporcionalmente el gravamen de la pena. Las injustas estructuras sociales, la tragedia de quienes soportan una vida infrahumana, el paro involuntario, la droga especialmente cuando a ella se llega tras situaciones de desesperación en beneficio de quienes impúnemente, en muchas ocasiones por desgracia, se enriquecen con su tráfico, etc.

\section{El proceso penal}

Cuando el proceso penal alcanza en la casación la culminación de su teleología, aunque con importantes restricciones, todas estas ideas se perciben, acaso, con mayor nitidez.

En ella se hacen realidad los principios de igualdad (STC de 29 octubre 1986) en cuanto garantizador de la interpretación de la ley por todos los tribunales del mismo orden, de exigencia de unas determinadas formalidades tendente a una más correcta ordenación del debate procesal, así como asegurar en beneficio del juzgador y de la parte contraria, la mayor claridad y precisión posibles en la comprensión de los motivos de la impugnación (STC 10 julio 86). Por otra parte, la tutela judicial efectiva se satisface siempre que se obtenga de los tribunales una resolución, aunque sea de inadmisión, fundada en derecho (STC 22 oct. 86).

Por otra parte la presunción de inocencia constituye una efectiva garantía del ciudadano frente a la arbitrariedad o precipitación de los jueces y tribunales. Sólo, como ya dijimos, una actividad probatoria de cargo, razonablemente suficiente advenida al proceso de forma legítima, conforme a las normas constitucionales y procesales puede destruir la presunción provisoria, "iuris tantum" de inocencia.

Todo ello es de aplicación general a lodos los derechos sancionadores. A nuestro juicio es indispensable una amplia reforma procesal penal inspirada en estos principios:

1) Perfecta integración en el proceso penal de los principios de defensa, de oralidad, de contradicción, impugnabilidad y acusatorio. $Y$ aplicación directa e inmediata del principio de presunción de inocencia. 
2) Separación de la investigación (a cargo del fiscal) y de la decisión que corresponde a los jueces que han de ejercer un cierto control sobre la primera fase en defensa de los derechos fundamentales de la persona.

3) Hacer del juicio oral la esencia misma del proceso penal.

4) Establecer con carácter general y sin excepciones, la doble instancia (24).

\section{La misión del juez penal}

No trato de plantear el tema de las parcelas que corresponden a cada uno de los poderes del Estado, cuya literalidad corresponde constitucionalmente al Pueblo, que tiene una extraordinaria dimensión e importancia, pero sí me gustaría hacer una breve reflexión, que ya he expuesto en varias ocasiones, sobre el cometido de los jueces.

Los jueces no hacen las leyes, las aplican, y han de hacerlo con los instrumentos que las propias normas facilitan a los juzgadores en su tarea de interpretarlas y aplicarlas.

Las resoluciones judiciales, en mi modesta opinión, no deben tener color político. La tonalidad política, necesaria, la tienen las leyes que se aplican, no las sentencias. Si la resolución de un tribunal se tacha de conservadora y "progre", según un criterio muy actual y creo que muy equivocado en muchas ocasiones, me parece que hacía bien el crítico en buscar la norma aplicada, su recto sentido y alcance, los hechos que sirven de presupuesto, y si honestamente piensa, respetando su contenido, que no se hizo una correcta interpretación de la norma,

(24) S. Tribunal Constitucional de 17 de julio 1986 y sentencias del Tribunal Supremo, Sala 24 de 1987 y 1988.

Ruíz Vadillo, Enrique: "Algunas breves consideraciones sobre el sistema acusatorio y la interdicción constitucional de toda indefensión en el proceso penal". Rev. "La Ley" 23 de octubre 1987.

Gimeno Sendra, Vicente y otros: "Derecho Procesal" Tomo II (Vol. I) El proceso penal 1. Tirant lo Blanch. 1987.

Ruíz Vadillo, Enrique: "La reforma del recurso de casación penal" en I. Congreso de Derecho Procesal de Castilla y León" dentro del tema de la "crisis de la Justicia y reforma del proceso penal", bajo la coordinación del Profesor Pedraz Penalva. Burgos Enero 1988. 
es lógica la crítica. Pero en otro caso la denuncia ha de hacerse no al juez, sino al legislador, que pudo arbitrar otra solución y no lo hizo.

A veces se dice, y se dice mal, a mi juicio, que las leyes son viejas, obsoletas, anticuadas, etc. Pero se olvida que una ley está vigente no por la voluntad del legislador que le dió vida, sino del actual que la mantiene. Por consiguiente si el estupro, los desórdenes públicos, determinados abusos a la libertad sexual de las personas, concretos delitos de injurias y desacatos, el escándalo público, etc. no respondieran a las exigencias legítimas de la comunidad (no siempre el que más voces da, ni quien tiene a su mano más eficaces medios de trasmisión de su queja, es el que tiene más razón), lo que hay que hacer es gestionar del Poder Legislativo, que es el Poder del Estado por excelencia y del que más cerca están los ciudadanos, que cambie las leyes, en este caso penales, y no hacer gravitar sobre los jueces la responsabilidad inmensa de no aplicar lo que supondría la quiebra total del principio de legalidad y del sistema todo, con gravísima destrucción de los pilares básicos del Estado de Derecho. Dar seguridad es uno de los fines esenciales del Derecho de ahí al principio de estabilidad o seguridad jurídica. (VSSTC de 22 de abril y 10 de julio 1987).

\section{Jurado}

El Jurado en su forma pura o mixta de Escabinato representa al pueblo mismo hecho juez. Si la futura ley acierta a una ordenación armónica y los ciudadanos se conciencian de su responsabilidad, su implantación puede y debe ser un paso importante en el correlato justicia-pueblo.

Si el Pueblo aplaude genéricamente su establecimiento pero no está dispuesto a participar con plenitud de derechos y de obligaciones en la condición de juez, el sistema fracasará.

Acaso una de las muchas y diferentes efectos positivos del Jurado, no sea el menos importante el del mayor conocimiento que de la administración de justicia tengan los ciudadanos y, por consiguiente, de las muchas y muy diversas complejidades que su recta aplicación supone.

Los jueces tenemos una obligación básica: administrar justicia bajo los parámetros de la Constitución y del resto del Ordenamiento Jurí- 
dico, entre ellos, por mandato de nuestra Ley Fundamental, el de su realización en el orden penal, y en los supuestos que marquen las leyes, a través del Jurado. Y en ello todos los jueces pondremos, cuando la norma se promulgue, el máximo empeño.

Pero que nadie piense, ni se haga ilusiones -que se transformarían después en desilusiones- que el Jurado va a resolver los muchos y graves problemas de la Justicia, que son básicamente de crecimiento y que carecen en general, de cualquier connotación patológica.

\section{Consideraciones finales}

Todas estas ideas son esenciales si queremos concluír en paz y con satisfacción para la mayor parte de los ciudadanos un proceso marcado por nuestra Constitución, de conformación de un Estado de Derecho, sin límites en el tiempo porque cuando la Ley Fundamental arraiga en la conciencia de los pueblos, ella misma es capaz de dar solución a los problemas que la dinámica social plantea.

Actualmente en el Ministerio de Justicia, un Grupo de Trabajo, del que tengo la satisfacción de formar parte, prepara una serie de reformas que tengo fundada esperanza de que cristalicen en realidades legislativas y coadyuven positivamente a este desarrollo político y social de España.

Como veréis, estas breves ideas no han sido otra cosa que un intento de reflexión comunitaria sobre una serie de problemas vigentes No interesa tanto el cómo de la solución, que en este caso tiene una referencia muy subjetiva y acaso equivocada, como la exposición sometida siempre al mejor y superior criterio de todos uds; queridos amigos que tan amablemente han tenido la atención de escucharme. Con un cierto sentido de síntesis tendría que dejar constancia de estas conclusiones que someto al mejor juicio de todos uds.

$1^{2}$ Que el tema definitivamente importante de cuales hayan de ser los hechos subsumibles en el Código Penal ha de resolverse buscando el mayor consenso social para que en la práctica su efectiva realización reciba una muy amplia aceptación. Siempre sobre la base de construir el delito bajo el presupuesto de la culpabilidad.

$2^{\mathbf{a}}$ No menos trascendente es el problema de las penas a imponer. En mi opinión procede evitar en lo posible las penas privativas de libertad 
que han de quedar reducidas al mínimo del mínimo, asociándose sólo aquellos comportamientos especialmente graves y trascendentes. Para las demás, aún mereciendo el calificativo de infracciones penales, deben establecerse sistemas punitivos alternativos, con un amplio sentido de imaginación creadora y mayor protagonismo de la multa en su versión de multa.

$3^{9} \mathrm{La}$ ejecución de las penas privativas de libertad, bajo la dirección de los jueces de Vigilancia Penitenciaria debe propiciar de verdad la reinserción, entendida como la aceptación voluntaria del sistema en cuanto a su respeto, no en orden a su adhesión, propiciándose el tercer grado o régimen abierto.

$4^{2}$ Hay que conseguir que el Pueblo, la comunidad, las gentes asuman el Ordenamiento Jurídico como algo propio, suyo, como lo es, creado en su provecho y utilidad.

Mi profundo agradecimiento al centro de la UNED en Melilla y a su Ilustre director D. Ramón Gavilán Aragón por su invitación y su extraordinaria amabilidad, y al querido vicedecano del Colegio de Abogados de esta Ciudad y jefe del Departamento de Derecho Penal del citado centro Universitario. D. Blas Jesús Imbroda Ortíz. Y un recuerdo y afecto con admiración a mi querido compañero D. Juan Antonio del Riego Fernández, presidente de la Sala $6^{\mathbf{a}}$ del Tribunal Supremo y a su hijo. D. José María, ilustre juez, que me trasmitieron el anticipo de esta invitación para mí tan grata y que tanto he agradecido por el honor que para mí ha representado.

Con esto termino, y si me permiten una última reflexión: La vida misma, dicen algunos excépticos, es la permanente consagración de la injusticia. Aquellos se quejan con amargura de que el mundo no avan$\mathrm{za}$, mientras estos lamentan la prisa con la que se mueve.

Al mismo tiempo existen unas normas legales que no nos satisfacen y otras que sentimos e intuímos como más justas y equilibradas que están por venir. Cuando el ideal de justicia se perfeccione, y somos todos los llamados a esta tarea, y el nivel de la legalidad y de la idealidad se aproximen, el mundo será, sin darnos cuenta mejor.

Muchas gracias al Excmo. Ayuntamiento de Melilla, a la Universidad y a uds. queridos amigos, sras y sres, por su amabilidad. 